\title{
Doces de ovos, doces de freiras: a doçaria dos conventos portugueses no Livro de Receitas da irmã Maria Leocádia do Monte do Carmo (1729)*
}

\section{Leila Mezan Algranti**}

A confecção de doces sempre ocupou um papel de destaque na imagem que se tem da vida conventual feminina na Idade Moderna e nos estudos sobre o cotidiano nos conventos em especial na Península Ibérica e na América latina - e faz parte indiscutível da história dessas instituições. Embora a maior parte das regras religiosas imponha até hoje dietas e tabus alimentares às reclusas, fazer doces, bolos e licores tornou-se uma tradição cultural e, principalmente, um elemento importante de sobrevivência econômica nessas instituições. Doces para casamentos, batizados e festas eram a especialidade das religiosas luso-brasileiras, a ponto de um ditado antigo no Rio de Janeiro, referindo-se ao famoso convento setecentista existente na cidade, afirmar: "no Convento da Ajuda só os doces são bons". 1

Comentando a arte de fazer doce das religiosas, Gilberto Freyre observou com sua tradicional perspicácia: "arte como a do próprio doce e a do próprio bolo, em Portugal, saía principalmente dos conventos de freiras; $e$, no Brasil, desenvolveuse tanto nos conventos, como em casas particulares". ${ }^{2}$ Buscando

\footnotetext{
* Apoio CNPq. Recebido para publicação em setembro de 2001.

** Professora do Departamento de História do IFCH e pesquisadora do Núcleo de Estudos de Gênero - Pagu/UNICAMP.

1 CoARACy,Vivaldo. Memórias da Cidade do Rio de Janeiro. Rio de Janeiro, $2^{a}$ ed., José Olympio, 1955, p.198.

2 FREYRe, Gilberto. Açúcar: uma sociologia do doce, com receitas de bolos e doces no Nordeste do Brasil. São Paulo, Cia das Letras, 1997 (1939), p.30.
} 
Doces de ovos, doces de freiras

entender essa tradição, ele explica que os "doces de freira" foram um dos maiores encantos da velha civilização portuguesa, que antes aprendera dos mouros a fabricar açúcar e a fazer mel, doce e bolo. ${ }^{3}$

O caderno de receitas da abadessa do Convento de Santa Clara de Évora, sóror Maria Leocádia do Monte do Carmo, além de ser um testemunho dessa tradição - já que é integralmente dedicado a receitas de doces - proporciona um instrumento valioso de análise àqueles que se dedicam ao estudo da alimentação e das práticas culinárias no século XVIII. ${ }^{4}$ Como outros livros de cozinha, as receitas podem revelar persistências de hábitos, mas especialmente inovações no que concerne à alimentação de certos grupos sociais. Elas permitem ainda, uma etnografia da cozinha, o estudo dos apetrechos e dos utensílios, dos produtos (sua moda, decadência, substituição), da forma de preparar os alimentos, assim como a análise do sentido e da lógica da transmissão escrita dessas práticas alimentares. Enfim, o livro de cozinha encerra hoje, como observou Maria José Azevedo Santos, "uma das principais fontes de conhecimento do viver do homem medieval e moderno".

Mas se os livros de cozinha proporcionam uma história do gosto, dos produtos e das formas de cozinhar, eles também possuem uma história que envolve sua produção e recepção. Este é um dos pontos instigantes do caderno de receitas de sóror Maria Leocádia, redigido pela escrivã do convento. Talvez tenha sido copiado de outros registros antigos do convento, por ordem da abadessa; talvez fossem receitas compartilhadas pelas religiosas $e$ transmitidas oralmente há muitas gerações, como sugere o título

3 ID., IB., p.34.

4 Cf. Biblioteca Nacional de Lisboa, códice 10763, Livro das Receitas de Doces e Cosinhados vários deste Convento de Santa Clara de Évora, sóror Maria Leocádia do Monte do Carmo, Abadessa. Santa Clara de Évora 26 de outubro de 1729. Ver também a publicação fac símile com introdução e notas de Manuel Silva Lopes. In: Curiosidades \& Velharias, série Especial 1, Lisboa, Barca Nova, 1988. 
do manuscrito existente na Biblioteca Nacional de Lisboa. De qualquer forma, trata-se de uma compilação de receitas, algumas cedidas por religiosas de outras instituições como indicam os nomes das receitas - exigência natural do saber culinário codificado, registrado pela palavra escrita. Mas certamente denota uma intenção de preservação da memória da instituição e serve de guia a outras doceiras do convento. Receitas que deveriam ser bem guardadas e não reveladas a estranhos, pois significavam proventos ao convento, como faz questão de frisar sua "autora".

Ele se insere também na tradição européia de livros de cozinha, já que os primeiros tratados de cozinha - ou pelo menos as compilações de receitas culinárias - apareceram em forma manuscrita em diferentes países da Europa desde o início do século XIV, talvez até desde o fim do século XIII. Essas compilações técnicas foram escritas por cozinheiros profissionais, ainda que tenham sido escritas por ordem de seu senhor e com a ajuda de um profissional da escrita. ${ }^{5}$ Exatamente como sucede ao livro do Convento de Santa Clara de Évora.

A imprensa, é claro, multiplicou os exemplares desses livros técnicos e logo eles passaram a tratar de cada uma das artes ligadas à alimentação. No século XVI assiste-se ao desenvolvimento de uma verdadeira literatura intermediária especializada em cardápios, corte de carnes, arrumação da mesa, livros de mordomos, e todas profissões consideradas artes. ${ }^{6} \mathrm{Um}$ outro tipo de obra são as "compilações de segredos", que se multiplicam a partir do século XVI e tratam tanto de medicina, como de cosmética e de receitas de doces, e destinam-se às damas. São os antepassados dos "livros de copa" dos séculos XVII

5 Sobre os Livros de Cozinha e sua utilização para a história da alimentação ver REVEL, Jean François. Um Banquete de Palavras - uma história da sensibilidade gastronômica. São Paulo, Cia das Letras, 1996, pp.9-30.

${ }^{6}$ Hyman, Philip e Mary. Os Livros de cozinha na França entre os séculos XV e XIX. In: Flandrin, Jean Louis e MonTANARI, Massimo. (orgs.) História da Alimentação. São Paulo, Estação Liberdade, 1998, p.629. 
Doces de ovos, doces de freiras

e XVIII. ${ }^{7} \mathrm{Na}$ França e na Itália os "manuais de segredos" nunca se referem a receitas de sal, mas sim de doces, de frutas, de conservas e de especialidades açucaradas, durante muito tempo associadas aos remédios e, portanto, à terapêutica. ${ }^{8}$ Segundo, Philip e Mary Hyman,

essa mistura inscreve-se perfeitamente na lógica da antiga dietética em que o açúcar era considerado como facilitador da digestão. Assim, os confeitos, doces de frutas e outras guloseimas eram reservados para o último serviço de um jantar. ${ }^{9}$

Aos poucos, porém, vão se separando as três artes (cozinha, confeitaria e copa), principalmente na França, e o costume se espalha pela Europa, pois a influência dos livros franceses de cozinha é considerável, já que no século XVII, muitos desses livros são adaptações dos livros franceses, ou escritos por cozinheiros franceses desde a Dinamarca à Itália. ${ }^{10}$

Os livros de cozinha, no entanto, constituem um setor pouco importante da edição francesa e italiana, mas os exemplares existentes assistiram a reedições sucessivas indicativas de sua aceitação e popularidade. ${ }^{\zeta 1} \mathrm{O}$ mesmo sucede em Portugal entre o fim do século XVII - quando é editado o livro de Domingos Rodrigues, Arte de Cozinha, o qual possui múltiplas edições $e$ as últimas décadas do século XIX, quando aumentam

\footnotetext{
7 ID., IB.

8 FLANDRIN, Jean Louis. Da Cristandade ocidental à Europa dos estados (séculos XV a XVII). In: FlandRIN, J. L. e MonTANARI, M. (orgs.) História da Alimentação. Op. cit., especialmente o item "literatura para glutões e báquica", p.551.

9 Hyman, P. e M. Os Livros de cozinha na França... Op. cit., p.629.

${ }^{10}$ FlandRIN, J. L. Da Cristandade ocidental... Op. cit, p.551.

${ }^{11}$ Hyman, P. e M. Os Livros de cozinha na França... Op. cit., p.625.
} 
significativamente as obras de culinária e desponta uma literatura gastronômica propriamente dita. ${ }^{12}$

O Livro de Receitas da irmã Leocádia, de certa forma é um "livro de segredos" por conter "secretamente" as receitas mais famosas do convento, mas não traz receitas de mezinhas $e$ terapêuticas, como faz, por exemplo, o Livro de Cozinha da Infanta D. Maria (o mais antigo livro português de receitas). ${ }^{13} \mathrm{O}$ manuscrito do Convento de Santa Clara de Évora, dedicado apenas aos doces - embora o título mencione "outros cozinhados" -, denota o caráter de especialidade, já marcante nas publicações do século XVIII e, com grande probabilidade, também da cozinha deste convento. São dez receitas de doces, todas a base de muitos ovos e açúcar, como reza a tradição conventual, sendo que os nomes das receitas remetem ao universo do cotidiano das monjas: "queijinho do céu", "barriguinhas de freira", "fatias de Santa Clara", "bolo do paraíso", "manjar celeste", etc.

As receitas, por sua vez, envolvem produtos simples de serem obtidos em Portugal, ou nas colônias (amêndoas, açúcar, farinha de trigo e de milho, canela, cravo-da-índia, erva-doce, manteiga de vaca e de porco, leite). São doces tradicionais, semelhantes a outros presentes em livros de receitas portugueses, como as famosas barriguinhas-de-freira, os pastéis de nata, ou os manjares de leite (manjar celeste). Este último de origem incerta, mas segundo Maria José Azevedo Santos, já conhecido na Espanha e na França por volta do século XIV. ${ }^{14}$ Os "alfitetes de Santa Clara", da irmã Leocádia (termo de origem árabe,

${ }^{12}$ Sobre o assunto ver: RÊGO, Manuela. Livros Portugueses de Cozinha. $2^{\mathrm{a}}$ ed., Lisboa, Biblioteca Nacional, 1998; Rodrigues, Domingues. Arte de cozinha. Leitura, apresentação, notas e glossário por Maria da Graça Pericão e Maria Isabel Faria, Lisboa, Imprensa Nacional, 1987 (1680).

${ }^{13}$ Livro de Cozinha da Infanta D. Maria. Lisboa, Imprensa Nacional/Casa da Moeda, 1987 (século XV).

${ }^{14}$ Cf. SANTos, Maria José Azevedo. O mais antigo livro de cozinha português receitas e sabores. Apresentado nas Jornadas Bem-Dizer e Bem-Comer, Coimbra 29/11 a 01/12 de 1991, p.81 
Doces de ovos, doces de freiras

registrado desde o século XIV, e que significa "bocadinho", "migalha"), assemelham-se aos "maçapães" ou bolinhos doces feitos com açúcar em ponto e amêndoas pisadas, que as clarissas quinhentistas de Santarém já produziam. ${ }^{15}$

Quanto aos vocábulos e utensílios culinários, vários deles aparecem no Livro de cozinha da Infanta D. Maria ${ }^{16}$ e da mesma forma que as receitas desse livro, as de Leocádia trazem alguns conselhos práticos às cozinheiras, ou cozinheiros menos experientes: acrescentar o leite "a pouco e pouco", ou engrossar "uma massa menos consistente com miolo de pão ralado" ${ }^{17}$

Mas o livro de receitas do Convento de Santa Clara de Évora revela algumas singularidades se comparado a outros livros e manuscritos do tipo. Primeiramente, trata-se de um registro institucional, com vistas à preservação e divulgação de um saber $e$ de práticas compartilhadas por mulheres reclusas, cujo contato com o mundo passava especialmente pelas cozinhas do convento; destina-se, portanto, ao uso interno do estabelecimento, ao contrário dos demais livros ou cadernos de receitas da época, escritos na sua quase totalidade por cozinheiros homens que viviam nas cortes e visavam um público amplo. Por outro lado, não deixa de ser também um testemunho da familiaridade das mulheres com a escrita e dos usos que faziam dela, numa época em que poucas mulheres eram letradas.

O livro de cozinha de irmã Leocárdia proporciona assim, múltiplas análises e reflexões, quer sobre as instituições de reclusão feminina $e$ as experiências das mulheres que nelas habitavam, quer sobre a história da alimentação e demais aspectos da vida cultural da época. Além disso, é tão saboroso ao leitor quanto o conteúdo que conserva. Àqueles que o utilizarem desejamos, portanto, bom proveito!

${ }^{15}$ ID., IB., p. 71.

${ }^{16}$ Ver o glossário que acompanha a edição citada de 1987, pp.167-244.

${ }^{17}$ Cf. Biblioteca Nacional de Lisboa, códice 10763, "Livro de Receitas de Doces e Cozinhados vários", op. cit., fl.5. 
Leila Mezan Algranti

\section{Transcrição do Documento}

Livro das Receitas de Doces e Cozinhados vários deste Convento de Santa Clara de Évora

Sóror Maria Leocádia do Monte do Carmo Abadessa ${ }^{18}$

Santa Clara de Évora, 26 de outubro de 1729

\section{Broas de Milho de Santa Clara}

Toma-se um arrátel de farinha de milho e mais outro, um arrátel de farinha de trigo, dois arráteis de açúcar, um púcaro de bom leite, cravo-da-índia e erva doce quanto baste para aromatizar. Amassa-se tudo muito bem, tempere-se de sal e façam-se as broas e mandem-se ao forno.

\section{Barriguinhas de Freiras}

Ponha-se um arrátel de açúcar em ponto de pasta. Tomam-se seis ovos com claras e dez gemas, tudo batido com uma porção de pão ralado, que não vá além de uma chávena. Leve-se ao lume e logo que principiar a ferver, vai-se untando o tacho em calda com manteiga para não pegar e deixe-se cozer a lume brando até ganhar por baixo uma camada aloirada.

\section{Alfitetes de Santa Clara}

Um arrátel de amêndoas sem casca, um arrátel de grão de bico. Arrátel e meio de açúcar branco, uma colher de sopa cheia de manteiga de vaca e 6 gemas de ovos e canela. Põe-se de véspera o grão de molho; no dia seguinte, antes de o cozer descasca-se, depois coze-se ou se passa por um ralador de batata ou se pisa

\footnotetext{
${ }^{18} \mathrm{Na}$ transcrição que se segue, a ortografia foi modernizada, mas a pontuação,
} expressões e sintaxe foram mantidas de acordo com o manuscrito original. 
Doces de ovos, doces de freiras

num gral. Toma-se das fartes deita-se em uma tigela. Toma-se em seguida a amêndoa e escalda-se para lhe tirar a pele. Depois corta-se em bocados pequenos com uma faca. Deita-se em um gral mui limpo e pisa-se, tendo o cuidado de ir deitando e um gral colherzinhas de água, para que a amêndoa não se faça em óleo; depois de bem esmagada, deita-se na mesma tigela onde tomas o grão; em seguida, leva-se ao lume dentro de uma gamela o açúcar a que se junta uma pequena porção de água pura para poder ferver. Quando estiver em um ponto não mui alvo ponto de pasta, deitam-se dentro as massas já pisadas, o grão e amêndoa, a manteiga e um bocadilho de canela em pó. Ferve-se tudo um pouco. Tira-se para fora do lume para se lhe ajuntarem as gemas bem batidas, mexendo para que fique tudo envolvido por igual. Volta ao lume, levanta a fervura e, se vê que a está massa pouco consistente, ajunta-se algumas colheradas a pouco e pouco de miolo de pão ralado. Não se deve deixar ficar mui vasto, porque quando esfria torna-se sólido. Está pronto.

\section{Fazer os pastéis:}

Com uma porção da dita farinha amassa-se e em estando pronta a "empegar-se" (sic.) qualquer forma (ilegível) massa tenra" (sic.). Passemos a fazer os pasteis. Estende-se um pouco de massa com um rolo, deixando o mais delgado possível. Em seguida deita-lhes em cima colheres de recheio e dobra-se a massa por cima fazendo os pastéis e recortando com uma carretilha fritam-se em banha para poderem crescer e polvilham-se com açúcar fresco fino.

\section{Queijinho do Céu}

Um arrátel de açúcar e 24 gemas de ovos, uma quarta de amêndoas, o ponto é alto, juntam-se a amêndoa, depois aquecem-se os ovos com um poucadinho de açúcar para continuar logo; a massa quer-se mais branda do que a das castanhas; quando se fez este, cortam-se hóstias redondas; cada 
queijo leva duas. Molha-se a hóstia com água e deita-se a massa; põe-se a outra hóstia; depois de estar pronta vai ao forno brando, depois de fria passa-se por açúcar em ponto.

\section{Trouxas d'ovos}

Batidas com varas e levantadas uma dúzia de claras de ovos, ajuntam-se-lhe as gemas, cascas de limão, flor de laranja coberta, tudo picado, piscadelas de amêndoa, açúcar fino, sal e uma gota de leite. Estando tudo bem misturado, ponha-se a cozer em manteiga clara e bem quente, depois de cozido ponha-se no seu prato e sirva-se vidrado com açúcar fino e pá quente.

\section{Pastelinhos de Nata}

Desfeitos em açúcar fino seis covilhetes de natas e quinze gemas de ovos, engrossa-se ao lume; guarneçam-se depois umas fôrmas de massa folhada, e metida a nata dentro, meta-se a cozer no forno; em a massa estando cozida e com boa cor, sirvam-se quentes.

\section{Fatias de Santa Clara}

As fatias se fazem nesta casa com o engenho de pão. A um arrátel de açúcar juntam-se 12 ovos e se batem, deitando umas pedrinhas de sal, até engrossar e muito. Verte-se-lhe depois um arrátel de farinha, ou menos se estão muito grossas (nunca é bom muita farinha), e com ela se lhes dá uma pequena batedeira na bacia, na qual vão ao forno de padeiro à saída do pão. $\mathrm{O}$ açúcar deve ser seco e os ovos muito frescos.

Pão de Bala com azeitonas das nossas irmãs do Convento de Santa Helena do Calvário, dada por a irmã sor Umbelina Inez de Jesus 
Doces de ovos, doces de freiras

Para 6 balas, um arrátel de amêndoas 12 arráteis de açúcar, 12 ovos e um arrátel de chila para recheio.

Um salamim de azeitona -

Uma quarta de amêndoas, um arrátel de açúcar, 2 ovos e uma pequena porção de cacau em pó.

$$
*_{-} *_{-} *
$$

Deitam-se em um tacho o açúcar e uma pequena porção de água e deixa-se ferver até chegar ao ponto de cabelo, e tira-se do lume . Pisa-se muito bem a amêndoa, junta-se lhe os dois ovos com as claras, e misturando tudo mui bem, deita-se a massa no tacho; vai novamente ao lume até dar consistência, não devendo deixar secar muito. Tire-se novamente do lume deixe-se arrefecer bem.

Noutro tacho deitam-se duas quartas de açúcar, o qual se deixa ferver até fazer ponto de pasta. Neste açúcar somam-se então as vulgares claras de ovos e no açúcar que fica deita-se o recheio de chila e mais 4 gemas, indo seguidamente no lume a ferver um bocadinho.

Quando frias as duas preparações, fendem-se os pães desta maneira: com farinha divide-se o maçapão em 12 bocados, 6 maiores que são os fundos e 6 mais pequenos que são as tampas. Nos maiores faz-se uma cavidade onde se deita uma camada de folhas, outra de chila, e uma terceira de folhas, após o que se tapam com a tampa ajeitando-se de maneira a formar um pão de vintém. Fendidos os 6 rolos, vão ao forno muito quente, mas só para assar, em um tabuleiro untado com manteiga de porco e de vaca.

\section{Bolo do Paraíso}

\section{Especialidade do Convento de Nossa Senhora do Paraíso}

2 arráteis e meio de açúcar em ponto de cabelo; tira-se do lume e desfaz-se um arrátel de amêndoas bem pisadas e 15 gemas de 
ovos, sendo 5 com claras. Vai depois ao lume até fazer custelo (sic.) pequeno, torna-se a tirar quando esteja nesse ponto $e$ mistura-se-lhe uma quarta de pão ralado e canela. Pulveriza-se uma tábua de farinha de trigo peneirada, e deita-se-lhe a espécie cobrindo-a de açúcar claro. Assim fica-se até ao dia seguinte em que se partem em talhadas e vai ao forno. Leva recheio ao meio.

\section{Manjar Celeste}

Convento de Santa Mônica

Especialidade da nossa irmã sor Theresa de Santa Ritta

2 quartas de requeijão e duas de açúcar; 6 ovos, gemas sem claras. Põe-se o açúcar em ponto de fio e deita-se-lhe o requeijão ralado; em fervendo tira-se do lume e deitam-se as gemas. Torna a ir ao lume a ferver outra vez. Tira-se depois do lume e deita-se em tigelinhas de barro pequenas, deixa-se a esfriar e vai ao forno a fartes.

\section{Termo}

Este livro se não entregará a outrem que não seja pessoa desta casa nem por cedência, nem por empréstimo por afetar os proveitos da feitura dos doces que nesta casa são feitos.

Santa Clara de Évora , 26 de outubro de 1729

Jesus Maria do Rosário

Escrivã 
Doces de ovos, doces de freiras

\section{Glossário $^{19}$ :}

Alfitete - migalha, bocadinho, bolinhas de massa de farinha e mel, cozidas com vapor e água a ferver.

Arrátel - antiga medida de peso, equivalente a 459 gramas.

Covilhetes - vaso pequeno de barro de figura côncava em que se costumam por doces. Também há covilhetes de metal, que são formas em que se fazem pastéis.

Fartes - bolos que levam o nome de fartes.

Gral - derivado do francês antiquado, graal, que queria dizer vaso de barro, mas em Portugal significava vaso de páu, em que se pisam adubos e vários ingredientes.

Púcaro - vaso a modo de taça em que se bebe. Em alguns dicionários se acha por púcaro uma espécie de jarra ou quarta em que se deita água.

Chila - abóbora pequena com a qual se faz doce.

${ }^{19}$ Bluteau, D. Raphael. Vocabulário Portuguez e Latino, CD Rom, Departamento Cultural da UERJ, 2000 (século XVIII). 